\title{
Changes in cranial CSF volume during hypercapnia and hypocapnia
}

\author{
R GRANT,* B CONDON,* J PATTERSON, D J WYPER, $\ddagger$ M D M HADLEY,* \\ G M TEASDALE $\dagger$
}

From the Magnetic Resonance Imaging Unit, ${ }^{*}$ University Department of Neurosurgery, $\dagger$ Institute of Neurological Sciences, Southern General Hospital, and Department of Clinical Physics and Bioengineering, $\ddagger$ Glasgow, Scotland, UK

SUMMARY Magnetic resonance imaging was used to measure the effect of inhalation of $7 \% \mathrm{CO}_{2}$ and hyperventilation with $60 \% \mathrm{O}_{2}$ on human cranial cerebrospinal fluid volume. During $\mathrm{CO}_{2}$ inhalation there was a reduction in the cranial CSF volume ranging from $0.7-23.7 \mathrm{ml}$ (mean $9.36 \mathrm{ml}$ ). The degree of reduction in cranial CSF volume was independent of the individual subject's increase in endexpiratory $\mathrm{pCO}_{2}$ or mean arterial blood pressure, in response to hypercapnia. During hyperventilation with high concentration oxygen the cranial CSF volume increased in all subjects (range $0.7-$ $26.7 \mathrm{ml}$, mean $12.7 \mathrm{ml}$ ). The mean changes in cranial CSF volume, induced by hypercapnia and hypocapnia, were very similar to the expected reciprocal changes in cerebral blood volume.

The original Monro-Kellie doctrine concerning intracranial volume was corrected by George Burrows ${ }^{1}$ in 1846 who, for the first time, incorporated the CSF and suggested that the blood and CSF volumes were reciprocally inter-related. Since then, cerebral blood volume has been estimated by various techniques, and changes described both in response to physiological stimuli and pathological conditions. ${ }^{23}$ Measurements of the total cranial CSF volume in humans have only recently become possible as a result of recent developments in magnetic resonance imaging (MRI). ${ }^{4}$

We have used MRI to observe the effects of vasodilation and vasoconstriction on total cranial CSF volume in normal human subjects. Our aims were to determine if indeed there were reciprocal changes in cranial CSF volume, and if so to determine their magnitude.

\section{Subjects and methods}

(a) Control studies

In order to ensure that changes in total cranial CSF volume were not related to the length of time in the recumbent position, 25 normal volunteers had cranial CSF volumes

Address for reprint requests: Dr Robert Grant, Magnetic Resonance Imaging Unit, Institute of Neurological Sciences, Southern General Hospital, 1345 Govan Road, Glasgow G51 4TF, Scotland, UK.

Received 22 January 1988 and in revised form 17 September 1988. Accepted 1 October 1988 measured immediately after lying down and again 15-20 minutes later while remaining recumbent.

(b) $\mathrm{CSF}$ volume and $\mathrm{CO}_{2}$ inhalation

Twelve healthy normal volunteers were studied. There were nine males (age range 19-34, mean 28.6 years) and three females (age range 20-41, mean 29.3 years). There were nog medical contraindications to MRI and all subjects gave written informed consent.

(c) CSF volume and hyperventilation during high flow oxygen Twelve healthy subjects were studied before and during hyperventilation with high flow oxygen. There were eight males and four females aged from 20-38 years (mean 29.1 years).

\section{CSF volume measurement by MRI}

Cranial cerebrospinal fluid volume was measured using the technique of Condon et al. ${ }^{4}$ All images were performed on a 0.15 Tesla resistive magnet (Picker International, Wembley) operating at $6.38 \mathrm{MHz}$ using a standard head coil. An inversion recovery sequence with a $300 \mathrm{~ms}$ delay time was combined with a Carr-Purcell data collect with an echo time of $400 \mathrm{~ms}$ and a repetition time of $5000 \mathrm{~ms}$ (IRCP300/400/ 5000). The result produces an image of CSF, with a contrast of greater than 200 to 1 between a unit volume of CSF and a unit of combined grey and white matter.

A phial containing a known volume of water at $37^{\circ} \mathrm{C}$ was strapped on the subject's head to act as a reference standard for CSF. The relaxation times are very similar, with a $T_{1}$ and $\mathrm{T}_{2}$ of $3499 \mathrm{~ms}$ and $2025 \mathrm{~ms}$ for water and $3302 \mathrm{~ms}$ and 2269 ms for CSF respectively. ${ }^{4}$ The subject was then centred in the head coil using an overhead positioning laser. A coronal pilot scan (SE40/200) lasting 0.4 minutes was performed to ensure the phial was placed centrally, that the patient was central in the imager and that the selected slice width enclosed the 


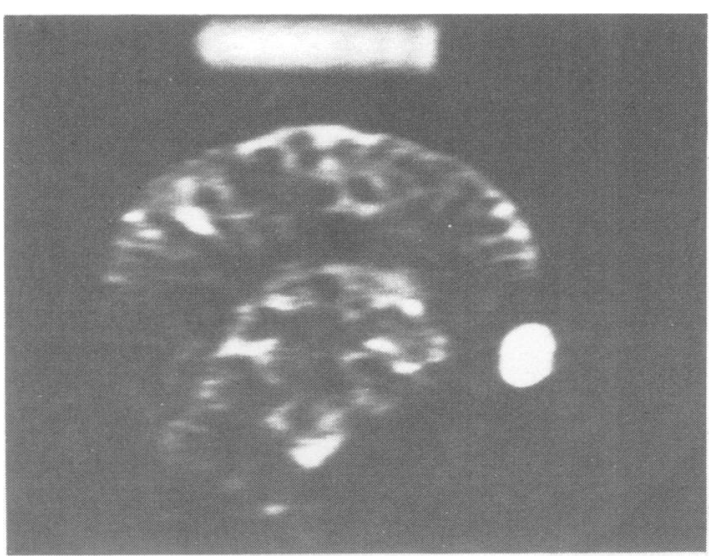

Fig 1 IRCP300/400/5000 sagittal MRI (slice select$18 \mathrm{~cm}$ ) demonstrating CSF only.

whole head. A sagittal image of the head (IRCP300/400/ 5000 ) was then obtained with an acquisition time of $5.3 \mathrm{~min}$. This produced an image of all cranial CSF (fig 1). Although presented as a two-dimensional image, because the slice thickness is $18 \mathrm{~cm}$, the image contains signal from the total cranial CSF volume. By manually drawing a computer generated region of interest (ROI) around the brain, the cranial CSF volume could be calculated using the following equation:

(Mean signal ROI - Mean background signal) $\times$ area of ROI (Mean signal phial - Mean background signal) $\times$ area of phial $\times$ volume of phial $(30 \mathrm{ml})$

\section{$\mathrm{CO}_{2}$ inhalation during $\mathrm{MRI}$}

The subject was positioned on the MRI couch and a sphygmomanometer cuff was placed around the left upper arm. Pulse rate, systolic, diastolic and mean blood pressure were recorded automatically, using a Critikon Dinamap 1846P Version 028, before entering the imager and then at minute intervals. A rubber mouthpiece was placed in the subject's mouth and connected to a two-way valve. A 3 metre length of tubing extended from the inspiratory limb of the two-way valve to outside the MRI radiofrequency shield (fig 2). The expiratory limb from the valve was connected to a 1 metre length of tubing which was open to the air.

During the assessment of "resting" cranial CSF volume, the inspiratory limb of the tubing was left open so that the subject was able to breathe fresh air. A repeat scan was taken after a cylinder containing $7 \% \mathrm{CO}_{2}$ was attached to a Douglas bag and the outlet from the Douglas bag was attached to the inspiratory limb of tubing to the subject. Carbon dioxide inhalation lasted for the duration of the second MR scan, that is, 5.3 minutes. End-expiratory $\mathrm{CO}_{2}$ was measured while resting and during $\mathrm{CO}_{2}$ inhalation using a capnograph.

\section{Hyperventilation $/ \mathrm{O}_{2}$ inhalation during $M R I$}

The method used was similar to that of $\mathrm{CO}_{2}$ inhalation but high flow oxygen was delivered at a flow rate of 10 litres/min via the inspiratory limb directly, without the use of the Douglas bag. A capnograph sensor was inserted between the two-way valve and Duo-Mask (Lifecare). During the first "resting" scan the inspiratory limb of the system was open to air and at the start of the second scan the high flow $\mathrm{O}_{2}$ was connected to the inspiratory limb and the subject asked to hyperventilate at a rate of approximately 30 breaths/min.

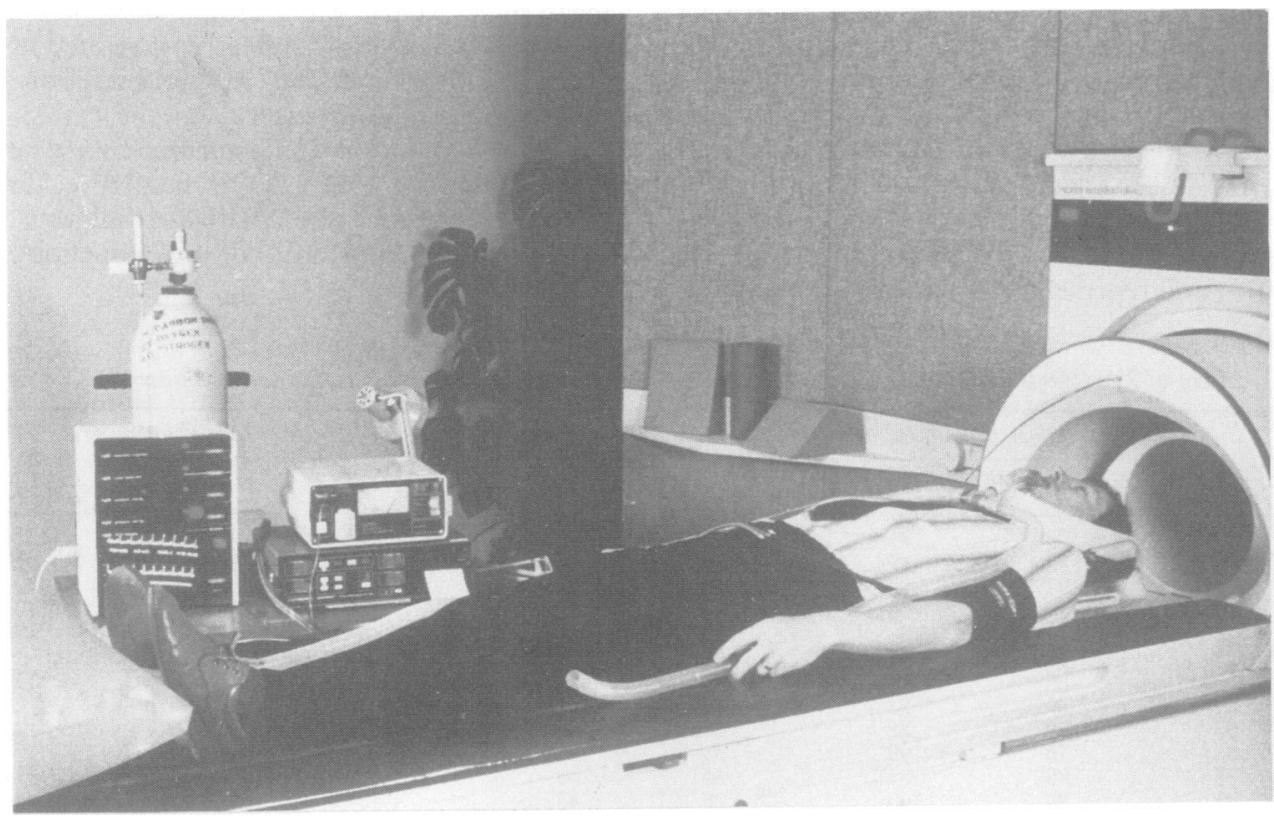

Fig 2 Equipment for patient monitoring and measuring $\mathrm{CO}_{2}$ responsiveness while in $M R I$. 
The average $\mathrm{O}_{2}$ concentration delivered at the mask was between $60-65 \%$.

It was not possible to obtain reliable measurements of endexpiratory $\mathrm{pCO}_{2}$ during hyperventilation because the high flow rate of the oxygen and fast respiratory rate did not allow sufficient time for the true expiratory $\mathrm{pCO}_{2}$ to register on the capnograph.

To gain an index of the degree of reduction in $\mathrm{paCO}_{2}$ "arterialised" venous blood sampling was measured in five of the volunteers before and during inhalation of oxygen at $101 /$ min while hyperventilating. The subject's arm was enclosed in an insulated bag and heated until a thermoelectrode, closely applied to the skin over the dorsum of the hand, gave a constant recording of skin temperature of $43^{\circ} \mathrm{C}$. Samples of "arterialised" venous blood were taken via a venous cannula which had been inserted into a vein on the dorsum of the hand close to the thermoelectrode.

While breathing air and after breathing oxygen for 5 minutes "arterialised" venous blood gases were measured using a Corning $178 \mathrm{pH} /$ blood gas analyser.

\section{Statistical methods}

The statistical package MINITAB was used to perform paired $t$ tests before and after inhalation of $\mathrm{CO}_{2}$ and before and after hyperventilation with $\mathrm{O}_{2}$, and to provide linear correlation coefficients. The data were normally distributed.

\section{Results}

Total intracranial CSF volume was not significantly different after 15-20 minutes of recumbency in 25 healthy volunteers-median difference $-2.8 \mathrm{ml}$ (interquartile range $1 \cdot 8,-6 \cdot 8$ ).

Resting total cranial CSF volumes before $\mathrm{CO}_{2}$ inhalation ranged from $52 \cdot 1$ to $160.8 \mathrm{ml}$ (mean 104.2). $A$ reduction in total CSF volume was recorded in all subjects following inhalation of $7 \% \mathrm{CO}_{2}$ (paired $t$ test: $\mathrm{T}=4.24, \mathrm{n}=12,0.001<\mathrm{p}<0.002$ ) (fig 3). The degree of change ranged from $-0.7 \mathrm{ml}$ to $-23.7 \mathrm{ml}$ (mean $-9.36 \mathrm{ml}$, SD 7.67). This was significantly different from the controls (Wilcoxon Mann Whitney, $p=0.017)$ and represented a percentage reduction in

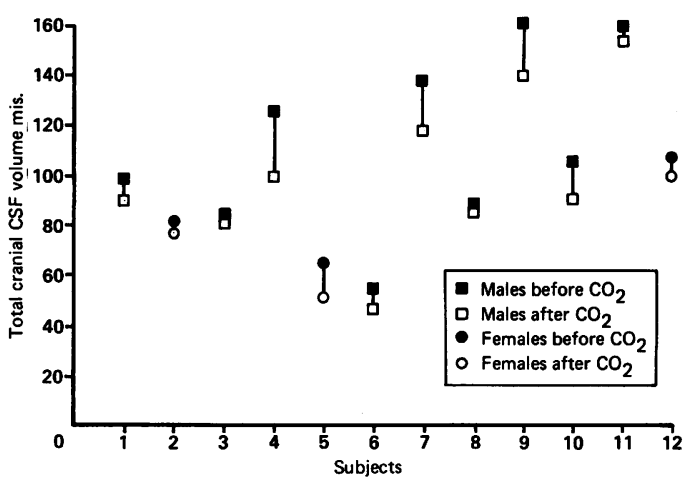

Fig 3 Total cranial CSF volumes before and after $\mathrm{CO}_{2}$ responsiveness.

total intracranial CSF volume of $0.9-19 \cdot 4 \%$ (mean $8.8 \%$ ). The results of the measurements of total cranial CSF volume and CBF in each subject are shown in table 1.

Subjects with large resting total cranial CSF volumes tended to have a greater reduction in CSF volume after $\mathrm{CO}_{2}$, however this just failed to reach significance at the $5 \%$ level (correlation coefficient 0 0.528 - minimum significant value of $r$ would be $0.576)$.

Mean arterial blood pressure (MABP), measured $\stackrel{\mathbb{Q}}{\stackrel{2}{-}}-$ automatically by the Dinamap while in the imager $T$ increased during hypercapnia in 11 of the 12 subjectso and did not alter in one case (table 1). As a group, theo mean rise in MABP was $9.25 \mathrm{~mm} \mathrm{Hg}$. There was not arelationship between the degree of reduction in tota $\overrightarrow{0}$ cranial CSF volume and the percentage increase in mean arterial blood pressure.

The end-expiratory $\mathrm{CO}_{2}$ increased by a mean of 13.3 (SD 4.2) $\mathrm{mm} \mathrm{Hg}$ after $7 \% \mathrm{CO}_{2}$ inhalation. There was not a correlation between individual subjects' increase in end-expiratory $\mathrm{CO}_{2}$ and the reduction in CSF volume.

Table 1 Effect of $7 \% \mathrm{CO}_{2}$ inhalation on $\mathrm{CBF}, \mathrm{MABP}$, end-expiratory $\mathrm{CO}_{2}$ and total cranial CSF volume

\begin{tabular}{|c|c|c|c|c|c|c|c|c|}
\hline \multirow[b]{2}{*}{ Subject } & \multirow[b]{2}{*}{ Age (yr) } & \multicolumn{2}{|c|}{ Mean Arterial BP $(\mathrm{mm} \mathrm{Hg})$} & \multicolumn{2}{|c|}{ End Expir $\mathrm{CO}_{2}(\mathrm{~mm} \mathrm{Hg})$} & \multicolumn{2}{|c|}{ Total CSF Volume (ml) } & \multirow{2}{*}{$\begin{array}{l}\% \text { Change } \\
\text { in } \\
\text { CSF volume }\end{array}$} \\
\hline & & Pre $\mathrm{CO}_{2}$ & Post $\mathrm{CO}_{2}$ & Pre $\mathrm{CO}_{2}$ & Post $\mathrm{CO}_{2}$ & Pre $\mathrm{CO}_{2}$ & Post $\mathrm{CO}_{2}$ & \\
\hline $\begin{array}{c}1 \\
2 \\
3 \\
4 \\
5 \\
6 \\
7 \\
8 \\
9 \\
10 \\
11 \\
12 \\
\text { Mean }\end{array}$ & $\begin{array}{l}19 \\
20 \\
23 \\
23 \\
27 \\
28 \\
29 \\
33 \\
33 \\
34 \\
35 \\
41 \\
28 \cdot 7\end{array}$ & $\begin{array}{l}75 \\
82 \\
79 \\
79 \\
85 \\
87 \\
85 \\
89 \\
79 \\
76 \\
88 \\
94 \\
83 \cdot 2\end{array}$ & $\begin{array}{c}81 \\
89 \\
83 \\
96 \\
98 \\
97 \\
97 \\
95 \\
88 \\
99 \\
88 \\
100 \\
92 \cdot 7\end{array}$ & $\begin{array}{l}27 \\
30 \\
32 \\
30 \\
33 \\
33 \\
40 \\
40 \\
38 \\
35 \\
35 \\
26 \\
33 \cdot 3\end{array}$ & $\begin{array}{l}50 \\
42 \\
45 \\
48 \\
44 \\
45 \\
49 \\
48 \\
50 \\
46 \\
48 \\
43 \\
46.5\end{array}$ & $\begin{array}{r}97.7 \\
80.5 \\
82.5 \\
123.3 \\
63.4 \\
52.1 \\
136.6 \\
87.0 \\
160.8 \\
102.5 \\
159.5 \\
104.8 \\
104.2\end{array}$ & $\begin{array}{r}90.6 \\
78.3 \\
81.8 \\
99.6 \\
51.1 \\
47.3 \\
118.7 \\
84.4 \\
140.5 \\
91.7 \\
154.1 \\
100.1 \\
94.9\end{array}$ & $\begin{array}{r}7.3 \\
2.7 \\
0.9 \\
19.2 \\
19.4 \\
9.2 \\
13.1 \\
2.8 \\
12.6 \\
10.5 \\
3.4 \\
4.5 \\
8.8\end{array}$ \\
\hline
\end{tabular}




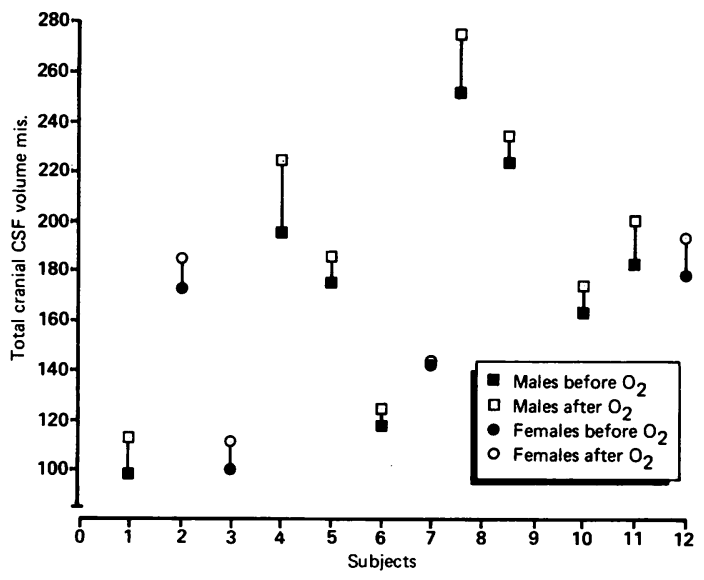

Fig 4 Total cranial CSF volumes before and after hyperventilation with oxygen.

Before hyperventilation with $60 \% \mathrm{O}_{2}$, total $\mathrm{CSF}$ volumes ranged from 99.5 to $253.3 \mathrm{ml}$ (mean $168.1 \mathrm{ml}$ ). During hyperventilation there was an increased total CSF volume in all subjects (fig 4) (paired $t$ test: $\mathrm{T}=$ $6.43, \mathrm{n}=12, \mathrm{p}<0.001)$ (table 2). The change in CSF volume ranged from $+0.7 \mathrm{ml}$ to $+26.7 \mathrm{ml}$ (mean + $12.7 \mathrm{ml}$ ). As a percentage of the total CSF volume this was +0.3 to $+13.6 \%$ (mean $+7 \cdot 6 \%)$. Subjects with a large initial CSF volume tended to show the greatest response but this was not significant (correlation coefficient 0.539 ).

The effect of hyperventilation on mean arterialised venous $\mathrm{pCO}_{2}$ was to produce a decrease in $\mathrm{pCO}_{2}$ from a mean of $40.05 \mathrm{~mm} \mathrm{Hg}(\mathrm{SD} 0.95, \mathrm{n}=5)$ before hyperventilation to $29.85 \mathrm{~mm} \mathrm{Hg}(\mathrm{SD} 1 \cdot 15, \mathrm{n}=5)$ after. The technique only gave an approximation of the reduction in arterial $\mathrm{pCO}_{2}$ and was of limited reliability.

Table 2 Cranial CSF volume and hyperventilation $/ \mathrm{O}_{2}$

\begin{tabular}{|c|c|c|c|c|}
\hline \multirow[b]{2}{*}{ Subject } & \multirow[b]{2}{*}{ Age (yr) } & \multicolumn{2}{|c|}{ Total Cranial CSF Volume ( $\mathrm{ml})$} & \multirow{2}{*}{$\begin{array}{l}\% \text { Change } \\
\text { in CSF } \\
\text { volume }\end{array}$} \\
\hline & & Resting & $\mathrm{O}_{2} /$ Hyperventilation & \\
\hline $\begin{array}{c}1 \\
2 \\
3 \\
4 \\
5 \\
6 \\
7 \\
8 \\
9 \\
10 \\
11 \\
12 \\
\text { Mean }\end{array}$ & $\begin{array}{l}20 \\
24 \\
26 \\
26 \\
28 \\
29 \\
29 \\
30 \\
31 \\
32 \\
36 \\
38 \\
29 \cdot 1\end{array}$ & $\begin{array}{r}99.5 \\
172.7 \\
100.6 \\
196.3 \\
177.1 \\
119.7 \\
143.2 \\
253.3 \\
224.4 \\
166.1 \\
183.4 \\
180.6 \\
168.1\end{array}$ & $\begin{array}{l}111.9 \\
183.7 \\
111.3 \\
223.0 \\
187.0 \\
126.4 \\
143.9 \\
274.3 \\
236.4 \\
174.4 \\
201.7 \\
195.1 \\
180.8\end{array}$ & $\begin{array}{r}12.5 \\
6.4 \\
10.6 \\
13.6 \\
5.1 \\
5.6 \\
0.5 \\
8.3 \\
5.3 \\
5.0 \\
10.0 \\
8.0 \\
7.6\end{array}$ \\
\hline
\end{tabular}

Discussion

The validity of the Monro-Kellie concept and its later modifications provoked considerable controversy. The original doctrine that cerebral blood volume remained constant in all circumstances was continued by Adamkiewicz, ${ }^{6}$ Leonard Hill ${ }^{7}$ and even by Weed. ${ }^{8}$ By contrast, Burrows' view that blood volume and CSF volume were variable, with the latter changing reciprocally in response to blood volume changes, was supported by Bergmann' and by Roy and Sherington. ${ }^{10}$ Our findings of a consistent reduction in CSF volume with hypercapnia and of an increase in CSF volume during hyperventilation directly confirm Burrows' modification of the Monro-Kellie concept and also indicate the magnitude of the reciprocal interactions between CSF volume and cerebral blood volume in normal human subjects. The absence of a systematic change in CSF volume after lying flat for several minutes accords with previous observations. These showed that the redistribution of CSF on lying flat was very small, occurred quickly, and stabilised in under one second."

A number of mechanisms may contribute to the changes in CSF volume we observed with hypercapnia and hyperventilation. The magnitude, as well as direction of change observed, supports a relationship with expected changes in cerebral blood volume. These were not measured in this study, and are difficult to perform in man. Reported values under normocapnia have shown cerebral blood volumes ranging from $4.2 \mathrm{ml} / 100 \mathrm{~g}$ brain to $7.0 \mathrm{ml} / 100 \mathrm{~g}$ brain. ${ }^{1213}$ Greenberg et al ${ }^{5}$ used emission tomography and ${ }^{99 m} \mathrm{Tc}$ labelled red blood cells to measure local cerebral blood volume simultaneously in multiple regions of the brain. They studied ten male volunteers and found that in all subjects $\mathrm{CO}_{2}$ inhalation increased cerebral blood volume and this was decreased by hyperventilation. The change in blood volume was $0.0495 \mathrm{ml} / 100 \mathrm{~g}$ brain per $\mathrm{mm} \mathrm{Hg} \mathrm{paCO}$. Assuming an average brain weight of $1400 \mathrm{~g}$, an increase in cerebral blood volume of $9.2 \mathrm{ml}$ would result from the increase in end-tidal $\mathrm{CO}_{2}(13.25 \mathrm{~mm} \mathrm{Hg})$ that occurred in our subjects. This is remarkably close to the observed mean decrease in cranial CSF volume, $9.36 \mathrm{ml}$. Measurement of the changes in end-tidal $\mathrm{pCO}_{2}$ during $\mathrm{CSF}$ volume measurements was not possible during hyperventilation. On the basis of the change in arterialised venous $\mathrm{pCO}_{2}$ under similar conditions $(-10 \cdot 2 \mathrm{~mm} \mathrm{Hg})$ the predicted reduction in cerebral blood volume would be by $7.07 \mathrm{ml}$. The mean increase in cranial CSF volume during hyperventilation, $12.7 \mathrm{ml}$, is a difference from predicted of only $3 \%$ of total cranial CSF volume. As well as the possibility of the data being underestimates of the changes in $\mathrm{paCO}_{2}$ and cerebral blood volume during hyperventilation, the difference may also reflect 
variability amongst different subjects. The precise alteration in cerebral blood volume and CSF volumes in individuals will depend upon differences in brain size, in intracranial compliance, and in vascular responsiveness to changes in arterial $\mathrm{CO}_{2}$ tension. Serial CSF measurements with varying $\mathrm{pCO}_{2}$ in one subject may help to establish the relationship between $\mathrm{paCO}_{2}$ and CSF volume.

The most likely mechanism through which cranial CSF volume changes in response to an alteration in cerebral blood volume is as a result of a displacement into or from the spinal subarachnoid space. The latter is distensible and interacts rapidly with changes in intracranial volumes. ${ }^{14}$ Changes in $\mathrm{paCO}_{2}$, either directly or through changes in intracranial pressure, may also affect reduction and absorption of CSF. Nevertheless, although hypercapnia reduces CSF production, ${ }^{15-17}$ the CSF formation rate is only approximately $0.3 \mathrm{ml} / \mathrm{min},{ }^{18}$ therefore this mechanism is unlikely to have been responsible for the reductions in intracranial CSF volume we observed.

We conclude that magnetic resonance imaging can be used to measure changes in intracranial CSF volumes in response to physiological stimuli and that the results obtained during acute manipulations of $\mathrm{paCO}_{2}$ correspond well with expected changes both in direction and magnitude.

This study was supported by grants from the Medical Research Council (ID81), the Greater Glasgow Health Board, the University of Glasgow and the Scottish Hospitals Endowment Research Trust.

\section{References}

1 Burrows G. On Disorders of the Cerebral Circulation, London, 1846. From Lundberg N. The Saga of the Monro-Kellie Doctrine. In: Ishie S, Nagai H, Brocks M, eds. Intracranial Pressure V. Berlin: Springer-Verlag, 1983:68-75.

2 Smith AL, Neufeld GR, Ominsky AJ, Wollman H. Effect of arterial $\mathrm{CO}_{2}$ tension on cerebral blood flow, mean transit time and vascular volume. J Appl Physiol 1971;31:701-7.

3 Kuhl DE, Reivich M, Alavi A, Nyary I, Stamm MM. Local cerebral blood volume determined by three dimensional reconstruction of radionuclide scan data. Circulation Research 1975;36:610-9.

4 Condon B, Patterson J, Wyper D, Hadley D, Grant R, Teasdale GM, Rowan J. Intracranial CSF volumes determined using magnetic resonance imaging. Lancet 1986;i:1355-8.

5 Greenberg JH, Alavi A, Reivich M, Kuhl D, Uzzell B. Local cerebral blood volume response to carbon dioxide in man. Circulation Research 1978;43:324-31.

6 Adamkiewicz A. Die Lehre vom Hirndruck und die Pathologie der Hirnkompression. Sitzungsher. Kaiserl Akad der Wissensch 1883;88:11-98 and 231-355.

7 Hill L. The Physiology and Pathology of the Cerebral Circulation. London, 1896.

8 Weed L. Some limitations of the Monro-Kellie hypothesis. Arch Surg 1929;18:1049-68.

9 Bergmann E von. Uber den Hirndruck. Langenbecks Archiv fur Klinische Chirurgie 1885;32:705-32.

10 Roy CS, Sherrington CS. On the regulation of the blood supply of the brain. J Physiol (Lond) 1890;11:85-108.

11 Magnaes B. Movement of cerebrospinal fluid within the craniospinal space when sitting up and lying down. Surg Neurol 1978;10:45-9.

12 Nylen G, Hedlund S, Regnstrom O. Cerebral circulatioro studies with labelled red cells in healthy males. Circula tion Research 1961;9:667-74.

13 Matthew NJ, Meyer JS, Bell RL, Johnson PC, Neblet CR. Regional cerebral blood flow and blood volume measured with the gamma camera. Neuroradiologg 1972;4:133-40.

14 Martins AN, Wiley JK, Myers PW. Dynamics of the cerebrospinal fluid and the spinal dura mater. $J$ Neurot5 Neurosurg Psychiatry 1972;35:468-73.

15 Oppelt WW, Maren TH, Owens ES, Rall DP. Effects of acid-base alterations on cerebrospinal fluid production. Proc Soc Exp Biol Med 1963;114:86-9.

16 Davson H, Hollingsworth G, Segal MB. The mechanism of drainage of cerebrospinal fluid. Brain 1970;93: 665-78.

17 Hochwald GM, Sahar A. Effect of spinal fluid pressure on cerebrospinal fluid formation. Exp Neurol 1971; 32:30-40.

18 Cutler RWP, Page L, Galicich J, Watters GV. Formation and absorption of cerebrospinal fluid in man. Brain 1968;91:707-20. 